\title{
Lymphoepithelioma-like carcinoma of the skin in a Polish patient
}

\author{
Michał Sobjanek ${ }^{1}$, Magdalena Dobosz ${ }^{1,2}$, Rafał Pęksa ${ }^{3}$, Małgorzata Sokołowska-Wojdyłoํ․ Anna Kowalczyk ${ }^{4}$, \\ Igor Michajłowski ${ }^{1}$, Roman Nowicki ${ }^{1}$
}

${ }^{1}$ Department of Dermatology, Venereology and Allergology, Medical University of Gdansk, Gdansk, Poland

Head of Department: Prof. Roman Nowicki MD, PhD

${ }^{2}$ Department of Plastic Surgery, Medical University of Gdansk, Gdansk, Poland

Head of Department: Alicja Renkielska MD, PhD

3Department of Pathomorphology, Medical University of Gdansk, Gdansk, Poland

Head of Department: Prof. Wojciech Biernat MD, PhD

${ }^{4}$ Department of Oncology and Radiotherapy, Medical University of Gdansk, Gdansk, Poland

Head of Department: Prof. Jacek Jassem MD, PhD

\begin{abstract}
Lymphoepithelioma-like carcinoma of the skin (LELCS) is a very rare cutaneous neoplasm with limited metastatic potential. It presents distinctive histopathologic features similar to undifferentiated nasopharyngeal carcinoma and clinical similarities with other skin neoplasms. We present the first case of LELCS in Polish patients. A 72-yearold woman presented with a 12 months' history of painless, solitary tumor on the nose. A wide local excision was performed. There was no evidence of local recurrence 24 months after surgical treatment.
\end{abstract}

Key words: lymphoepithelioma-like carcinoma of the skin, surgery.

\section{Introduction}

Lymphoepithelioma-like carcinoma (LELC) is a malignant tumor with histological features resembling undifferentiated nasopharyngeal carcinoma and presents outside the nasopharynx including the stomach, salivary glands, lungs, thymus, uterine cervix, larynx, and urinary bladder. Lymphoepithelioma-like carcinoma very rarely localizes on the skin. Less than 70 cases of this tumor have been reported [1]. Lymphoepithelioma-like carcinoma of the skin has not been reported in the Polish medical literature yet.

\section{Case report}

A 72-year-old female patient presented with a tumor on her nose with a 12 months' history and was consulted in the Department of Dermatology, Venereology and Allergology, Medical University of Gdansk. Clinically, the lesion presented as firm, $1 \mathrm{~cm}$ in diameter, skin-colored tumor (Figure 1). The lesion was moveable over underlying tissues, painless and did not give any nasopharyngeal symptoms. Cervical lymph nodes were not palpable. Incisional biopsy revealed histopathologic features of LELCS.
The patient was operated in the Department of Otolaryngology, Medical University of Gdansk. The tumor was excised with $1 \mathrm{~cm}$ margins with nasal mucosa. There was no evidence of local recurrence 24 months after treatment. Histopathological examination of the excised tumor revealed well-defined aggregates of epithelial cells with no connection with the epidermis surrounded by a dense lymphoid infiltrate. Tumor cells presented a rich amount of eosinophilic cytoplasm, large, vesicular nuclei and prominent nucleoli (Figures 2, 3).

\section{Discussion}

Lymphoepithelioma-like carcinoma was first reported in 1988 by Swanson et al. [2]. Authors described 5 cases of cutaneous tumors which were histopathologically similar to nasopharyngeal lymphoepithelioma. Lymphoepithelioma-like carcinoma has uncharacteristic clinical features, most cases present as a solitary, erythematous, firm nodule or plaque, with telangiectasia or ulceration. Although the tumor has a predilection to the skin of the face and scalp (90\%), other locations, like the arm, trunk, and penis have also been reported. Lymphoepithelioma-like carcino-

Address for correspondence: Michat Sobjanek MD, PhD, Department of Dermatology, Venereology and Allergology, Medical University of Gdansk, 7 Debinki St, 80-211 Gdansk, Poland, phone: +48 58349 25 80, fax +48 58349 25 83, e-mail: sobjanek@wp.pl Received: 3.07.2013, accepted: 20.11.2013. 
ma does not show a sex predilection and usually affects older adults (mean age: 72, range: 39-97) [1, 2].

Etiopathogenesis of the tumor is unclear, and, unlike the nasopharyngeal carcinoma, LELCS seems not to be associated with Epstein-Barr virus (EBV) [3]. Aoki et al. [4] described a case with EBV genomes in neoplastic cells, detected by polymerase chain reaction (PCR) and in situ hybridization. It is suggested that LELCS is a not distinct clinicopathological entity but rather a specific histopathologic pattern [5].

Characteristic features in the histopathological picture include nests, cords or sheets of mitotically active polygonal epithelioid cells with amphophilic to eosinophilic cytoplasm, hyperchromatic nuclei, coarse chromatin granules and prominent nucleoli. The tumor is located in the dermis without connection to the overlying epidermis. Despite characteristic histologic features, the histogenesis of LELCS remains unclear although there are theories concerning its adnexal and epidermal origin. Neoplastic epithelioid cells showed an expression of cytokeratins (AE 1/AE3, CK5/6) confirming epithelial differentiation. There is also characteristic dense lymphocytic infiltrate [4-8].

The differential diagnosis includes basal cell carcinoma, squamous cell carcinoma, Merkel cell carcinoma, amelanotic melanoma, malignant lymphoma, Hodgkin disease and cutaneous lymphoedema [5].

Management of LELCS should include a complete head and neck examination to exclude metastasis. A wide local excision remains the first-line treatment, although radiotherapy is reserved for local recurrences or lymph nodes metastasis [8]. Mohs micrographic surgery has also been used as an alternative method to the traditional resection of the tumor [9-12].

Lymphoepithelioma-like carcinoma has a relatively good prognosis with a very low metastatic rate. Among all reported cases, $78 \%$ of patients were free of the disease after the treatment. The local recurrence rate was $10 \%$. Only 2 patients developed lymph node metastases with a fatal outcome [12].

\section{Conclusions}

We report herein the first Polish case of LELCS with typical clinicopathological features and a relatively benign course.

\section{Conflict of interest}

The authors declare no conflict of interest.

\section{References}

1. Hall G, Duncan A, Azurdia R, Leonard N. Lymphoepithelioma-like carcinoma of the skin: a case with lymph node metastases at presentation. Am J Dermatopathol 2006; 28 : 211-5.

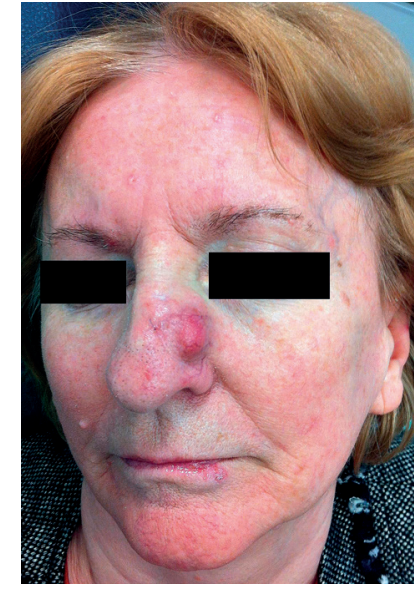

Figure 1. Clinical features of LELCS

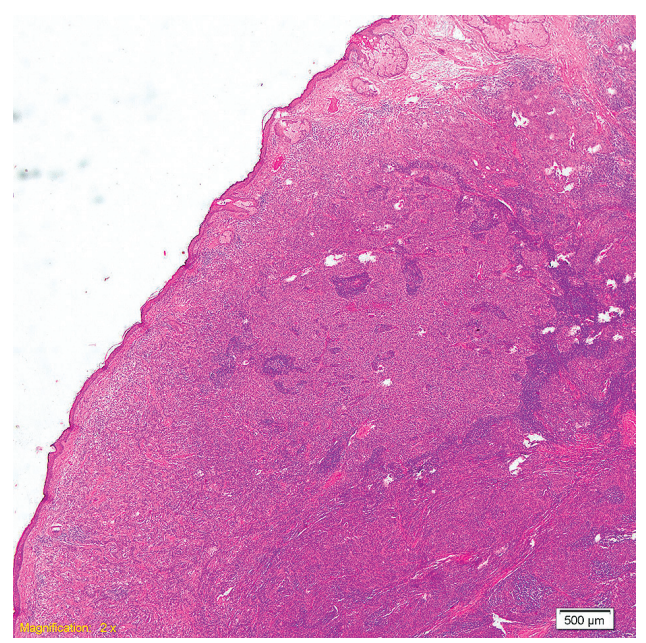

Figure 2. Intradermal tumor with expansive borders without epidermal ulceration. The tumor was composed of epithelioid neoplastic cells arranged in a syncytial growth pattern surrounded by a dense lymphocytic infiltrate

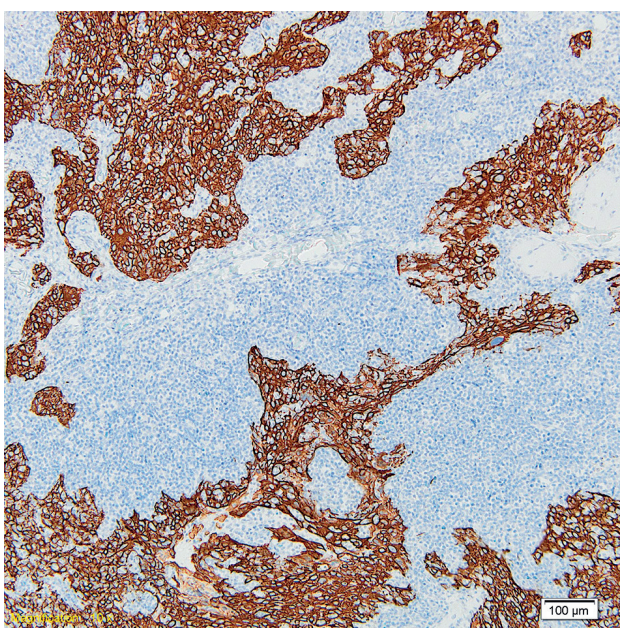

Figure 3. Neoplastic epithelioid cells showed an expression of cytokeratins (CK5/6), confirming epithelial differentiation 
2. Swanson SA, Cooper PH, Mills SE, Wick MR. Lymphoepithelioma-like carcinoma of the skin. Mod Pathol 1988; 5: 359-65.

3. Kazakov DV, Nemcova J, Mikyskova I, Michal M. Absence of Epstein-Barr virus, human papillomavirus, and simian virus 40 in patients of central European origin with lymphoepithelioma-like carcinoma of the skin. Am J Dermatopathol 2007; 4: 365-9.

4. Aoki R, Mitsui H, Harada K, et al. A case of lymphoepithelioma-like carcinoma of the skin associated with Epstein-Barr virus infection. J Am Acad Dermatol 2010; 62: 681-4.

5. Welch PQ, Williams SB, Foss RD, et al. Lymphoepithelioma-like carcinoma of head and neck skin: a systematic analysis of 11 cases and review of literature. Oral Surg Oral Med Oral Pathol Oral Radiol Endod 2011; 111: 78-86.

6. Wick MR, Swanson PE, LeBoit PE, et al. Lymphoepithelioma-like carcinoma of the skin with adnexal differentiation. J Cutan Pathol 1990; 18: 93-102.

7. Lind AC, Breer WA, Wick MR. Lymphoepithelioma-like carcinoma of the skin with apparent origin in the epidermis a pattern or an entity. Cancer 1999; 85: 884-90.

8. Ferlicot S, Plantier F, Rethers L, et al. Lymphoepithelioma-like carcinoma of the skin: a report of 3 Epstein-Barr virus (EBV)-negative additional cases. Immunohistochemical study of the stroma reaction. J Cutan Pathol 2000; 27: 306-11.

9. Lyle P, Nakamura K, Togerson S. Lymphoepithelioma-like carcinoma arising in the scar from a previously excised basal cell carcinoma. J Cutan Pathol 2008; 35: 594-8.

10. Takayasu S, Yoshiyama M, Kurata S, Terashi H. Lymphoepithelioma-like carcinoma of the skin. J Dermatol 1996; 23 : 472-5.

11. Glaich AS, Behroozan DS, Cohen JL, Goldberg LH. Lymphoepithelioma-like carcinoma of the skin: a report of two cases treated with complete microscopic margin control and review of literature. Dermatol Surg 2006; 32: 316-9.

12. Fenniche S, Zidi Y, Tekaya NB, et al. Lymphoepithelioma-like carcinoma of the skin in a Tunisian patient. Am J Dermatopathol 2006; 28: 40-4 